
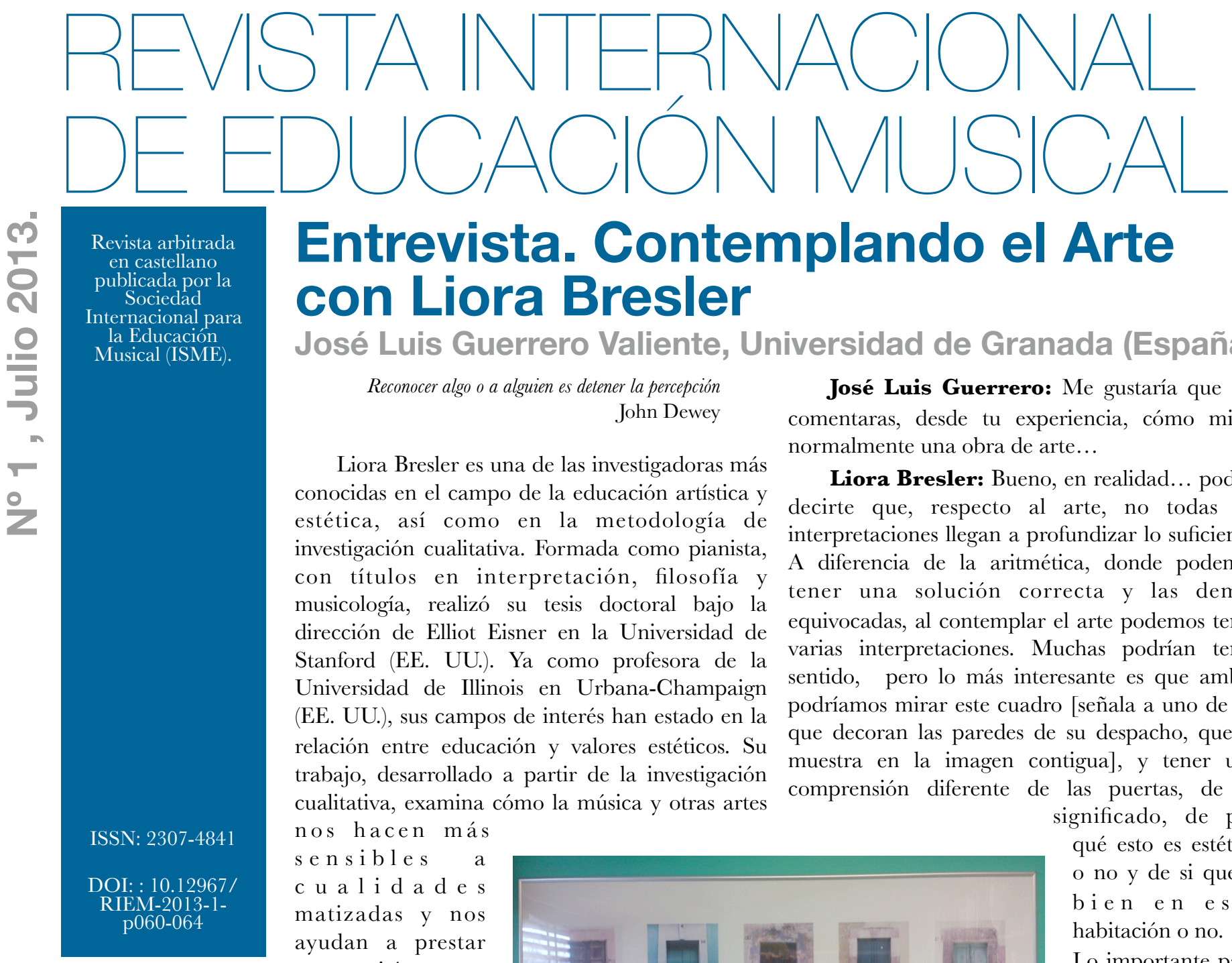

\title{
Entrevista. Contemplando el Arte con Liora Bresler
}

\section{José Luis Guerrero Valiente, Universidad de Granada (España)}

Reconocer algo o a alguien es detener la percepción John Dewey

Liora Bresler es una de las investigadoras más conocidas en el campo de la educación artística y estética, así como en la metodología de investigación cualitativa. Formada como pianista, con títulos en interpretación, filosofía y musicología, realizó su tesis doctoral bajo la dirección de Elliot Eisner en la Universidad de Stanford (EE. UU.). Ya como profesora de la Universidad de Illinois en Urbana-Champaign (EE. UU.), sus campos de interés han estado en la relación entre educación y valores estéticos. Su trabajo, desarrollado a partir de la investigación cualitativa, examina cómo la música y otras artes nos hacen más se nsibles a c u a l i d a d e s matizadas y nos ayudan a prestar a tención y "conectar" con lo que estudiamos. Recientemente se ha interesado en la i n i c i a t i v a emprendedora aplicada al ámbito académico y educativo.

El pasado 4 de diciembre tuve la oportunidad de entrevistarla. Con cita previa, a la una de la tarde me dirijo a la Facultad de Educación para encontrarme con ella, ocupando un hueco en su más que apretada agenda. Entro en su acogedor despacho y nos sentamos en una pequeña mesita blanca y redonda situada nada más entrar a la izquierda. Como parte del mobiliario, además de sus estanterías de libros, su ordenador, algunos ficheros y fotos de familia, se encuentran, inseparables de sus conversaciones, cajas de té aromático, bombones y una tableta de chocolate de algún país nórdico. Creo que es una invitación, no sólo a comer y tomar el té juntos, sino a hacer de esa conversación un momento entrañable que merezca la pena. Y desde luego que esta entrevista lo fue, no sólo por su forma de contemplar el arte, sino la vida.
José Luis Guerrero: Me gustaría que me comentaras, desde tu experiencia, cómo miras normalmente una obra de arte..

Liora Bresler: Bueno, en realidad... podría decirte que, respecto al arte, no todas las interpretaciones llegan a profundizar lo suficiente. A diferencia de la aritmética, donde podemos tener una solución correcta y las demás equivocadas, al contemplar el arte podemos tener varias interpretaciones. Muchas podrían tener sentido, pero lo más interesante es que ambos podríamos mirar este cuadro [señala a uno de los que decoran las paredes de su despacho, que se muestra en la imagen contigua], y tener una comprensión diferente de las puertas, de su significado, de por qué esto es estético o no y de si queda bie $\mathrm{n}$ e $\mathrm{n}$ e s t a habitación o no.

Lo importante para mí e s cómo interactuamos con la obra de arte, si nuestra actitud nos a yud a sólo a hacerlo con nosotros mismos o con la obra de arte en sí. La obra de arte es una invitación a tener un diálogo o una conversación con ella, y en ese proceso, con nosotros mismos.

Por ejemplo, algunos de mis estudiantes quizás mirarían el cuadro y dirían: "esto me recuerda a la casa donde me crié", y podrían hablar durante una hora o dos sobre la casa donde crecieron, pero no estarían realmente mirando la obra de arte y su contexto. Estarían volviendo a su infancia sin interactuar realmente con la obra. Sólo lo estarían haciendo con ellos mismos.

Otro ejemplo podría ser que yo, cuando escucho Kesterday de Los Beatles, podría hablar de la primera vez que fui a una fiesta y bailé esa canción, podría hablarte sobre esa experiencia, pero eso no diría nada sobre el Yesterday de Los Beatles como obra musical.

Para mí, en mis clases, la idea de enseñar arte es aprender a entregarnos e interactuar con él tanto como podamos. Es como en una 
conversación profunda o en una entrevista. El entrevistador podría hacer una serie de preguntas, poner la grabadora y dejar al entrevistado que hablara durante horas... Pero, en realidad, no te escucharía, no hablaría contigo cuando te hiciera las preguntas y simplemente seguiría un guión. No sería una verdadera entrevista o una conversación.

JLG: En este diálogo con el arte ¿podríamos decir que hay diferentes niveles o formas de hacerlo?

LB: Sí, estás en lo cierto. Hay muchos niveles de contemplar el arte pero, para mí, lo que es importante, como persona, e incluso mucho más como profesora es que, cuando miro una obra de arte o tengo una conversación, yo quiero hablar contigo, intento pensar en ti. La idea que deseo transmitir es que el arte me invita a experimentar lo que yo no sería capaz de hacer completamente sola. Me expande.

JLG: Entonces, de alguna manera, ¿es el arte una invitación para comprendernos un poco mejor a nosotros mismos?

LB: El arte me invita a ver y escuchar más del mundo exterior. En ese proceso, consigo ver a menudo mi yo más profundo (emociones, pensamientos, conexiones entre ideas, cosas a las que estoy atada...). Podría desarrollar esta idea diciendo que, cuando termine de ver esto [el cuadro de su despacho], no voy a ser exactamente la misma persona que era cuando empecé a verlo.

No estoy diciendo que si se hace de otra forma (con una mirada superficial, no dialógica) esté mal, sino que, en la vida, la vida de las personas, mi vida, es común hacer actividades que no llevan a un despertar. Tú puedes decir que haces esta o aquella actividad sin más. Pero a mí el arte que me gusta es aquél que me invita realmente a reconsiderar o pensar algo que yo no haría de otra forma. Cuando compré este cuadro [el de su despacho] yo pensé "es realmente interesante", y ahora pienso que las puertas [del cuadro] son como puertas dentro de mi mente... son invitaciones. Cuando tengo algo o conozco a alguien, que cobra significado para mí, como Robert Stake, por ejemplo, lo considero como una obra de arte. Stake me invita a pensar en cosas en las que yo no pensaría si él no las dijera. O Magritte, o Dalí...

Hay una frase de John Dewey que me gusta muchísimo. Él dice: "reconocer algo o a alguien es detener la percepción". Reconocer sería... ahora estoy viendo a José Luis, una puerta, un abrigo, chocolate... yo veo, yo reconozco, pero la percepción tiene que ver con cómo tú realmente estás mirando eso, con cómo estás hoy, con las cualidades de lo que está sucediendo aquí. Así, de esta manera, la percepción es más profunda y el reconocimiento es más una verificación de lo que hay; una taza, chocolate, un libro... es algo más rápido. Con la percepción tú lo comprendes...

El arte me proporciona una alternativa para salir del "piloto automático" de mi vida.

JLG: ¿Crees que es posible salir de ese piloto automático en cualquier momento?, ¿crees que todo el mundo puede hacerlo?

LB: Es una buena pregunta, una gran pregunta. Sin embargo, no voy a defender ese tipo de idealismo. Voy a abogar por mí misma y mis estudiantes diciendo que nosotros no queremos estar con ese "piloto automático" todo el tiempo. No estoy diciendo que deberíamos estar el 100\% del tiempo fuera de ese piloto automático, sino una parte del tiempo, quizás un 25\%, un $51 \%$ o un 49\%. La clave está en mantener un balance entre ambas ya que, si en cada momento estuviera "dialogando" [con el arte], no sería capaz de hacer el resto de las cosas que tengo que hacer en mi vida. Como profesora, lo que yo les digo a mis estudiantes es que una obra de arte puede ser una oportunidad para tener una buena conversación.

Cuando voy con ellos al museo les pido que estén 30, 40 o 45 minutos con una obra de arte que a ellos les guste y con otra que no les guste, y que vean qué sucede cuando se dan a sí mismos ese espacio de tiempo. También, durante la primera clase después de la visita, yo les hago todo tipo de preguntas, como qué es lo que ellos vieron, si se involucraron con el cuadro...y otras seis, siete, u ocho preguntas... y finalmente les digo: “¿qué te dijo el cuadro?, ¿qué le dijiste tú al cuadro?, ¿qué te llamó la atención del cuadro?". Y puedes hacer lo mismo con la música, a través de otro tipo de preguntas, guiones... pero la idea es que tengan una oportunidad para elegir una obra de arte, hablar sobre ella, estar 35 minutos frente a ella, y preguntarse estas cuestiones. Y no estoy hablando sólo del significado, que está bien, sino también sobre una invitación para mostrarles lo que sucede cuando se dan el tiempo para hacer algo diferente que no sea sólo hacer algo que nos urge - como tener las cosas hechas-, lo cual es lo que ellos o yo misma hacemos todo el tiempo, hoy, todos los días... Esto significa, en palabras de Maxine Greene y Parker Palmer, una oportunidad para conectar nuestros paisajes interiores con los exteriores.

JLG: Veo que tu interés está en hacerse buenas preguntas. ¿Qué papel juega el conocimiento teórico del arte o de las diferentes técnicas que normalmente forman parte de la educación puramente académica?

LB: Como profesora, para alguien que ha estado muchos años en el mundo de la educación, mi punto de vista no es muy diferente al de Dewey. Es fácil adquirir conocimientos con una educación formal. No voy a decir que eso está mal. Es más, te diré que, cuando era joven, me encantaba aprender sobre música, y puedo hablar bastante del tema, pero el poder de las artes tiene que ver con la forma en que Dewey habla de la experiencia vivida: con lo que la obra de arte puede hacerme a mí, con cómo vivo, cómo siento, con la energía. Creo que el conocimiento es muy importante, pero ése no es el fin, no es el objetivo. Cuando les pido a los estudiantes que vayan a un museo y elijan dos obras (una que les gusta y otra que no), después de eso, yo les doy varias tareas. Una es aprender acerca del contexto del artista, el periodo, las circunstancias de cómo fue hecha. El conocimiento de la vida del artista, de su contexto personal, cultural, artístico e histórico, a menudo permite llegar a capas más profundas de significado en una obra de arte o en una conversación. La búsqueda de conocimiento tiene un propósito y se hace para expandir relaciones y comprender más que por el conocimiento mismo. Ésa es para mí la clave.

Las experiencias que consigues al contemplar el arte son muy difíciles de obtener de otras fuentes. Eso es muy importante como profesora, ya que tiene un valor educativo y quiero estar segura de que mis estudiantes lo experimentan. Creo que si no lo experimentan en mi clase, puede que nunca lo hagan en sus clases de arte. Si tienen una educación similar a la que yo tuve, aprenderán técnicas o conocimiento proposicional, basado en hechos, pero creo que si no les 
invitamos a mantener esta otra relación con el arte, se pierden algo importante.

JLG: Por lo que comentas, para ti, el conocimiento en sí mismo no es siempre lo más importante. La forma en que contemplas el arte también puede hacer que profundicemos más en las experiencias de nuestras vidas, pero... ¿de qué manera ocurre esto y qué aporta a nuestro bagaje personal?

LB: Con el arte experimento todo tipo de sentimientos: enfermedad, potencia, energía, alegría, dolor... Las artes, más que cualquier otra cosa que pueda imaginar ahora, me ayudan a conectar con mi interior. Así, recuerdo la primera vez que vi las obras de Edward Munch, el noruego, o la primera vez que escuché el Réquiem de Mozart.

Cuando mi padrastro murió estaba muy afectada porque le quería muchísimo, y escuchaba el Réquiem de Mozart (él me trajo la grabación antes de caer enfermo y morir) para afrontar mi dolor. Me despertaba por las mañanas y antes de cepillarme los dientes, antes de desayunar, escuchaba el Réquiem, y lo ponía a un volumen muy elevado. Así conseguía la energía para levantarme y hacer las cosas.

El arte da significado a mi vida. Me invita a aprender más, tanto si son las puertas del cuadro de mi despacho o el Réquiem de Mozart. Me invita a saber, a hablar, a ver y a comprender más, conectando mi interior con el exterior.

Por ejemplo, me encanta Miró, y así, la primera vez que vi cuadros de él y también de Goya, experimenté algo como cuando uno dice "¡ah!”, porque sientes algo que resuena en tu interior. Por eso, ahora mi repertorio es mayor, pues puedo usar esas vivencias como marco de referencias para mi experiencia siguiente. Ellos pueden ayudarme muchísimo a ver, ya que me muestran que hay más emociones, más variaciones, más gradaciones...

Elliot Eisner escribió que nosotros creamos redes y luego pescamos, y que los pescados que nosotros cogemos son del tipo que nosotros podemos atrapar en nuestras redes, las cuales dependen de nuestra habilidad para tejerlas. Así, si nosotros tuviéramos más redes o más lentes, o si nos aproximáramos más a las obras de arte podríamos experimentar más emociones, debido a que alguien me habría dado esas lentes, esas redes.

De manera similar, Eisner cita a un famoso historiador, Ernst Gombrich, para decir que el pintor no pinta lo que puede ver sino que puede ver lo que puede pintar. Mi objetivo es expandir la capacidad para "pintar", metafóricamente hablando. Pintar para mí incluye la capacidad para conectar el exterior (pintura) con el interior (dándonos cuenta de nuestros más internos paisajes). Eso incluye reconocer muchas gradaciones de sentimientos diferentes. Por ejemplo, yo puedo decirme a mí misma..."estoy triste", y ponerme. Pero hay muchas maneras de estar triste y, si tengo diferentes repertorios de música, danza, literatura, diferentes gradaciones de colores... entonces, mi comprensión de la tristeza o alegría estará mucho más matizada.

El arte es interactivo debido a que si estoy expuesto a diferentes tipos de arte, soy capaz de ver más. Algunas personas piensan sobre todo en términos absolutos de felicidad o tristeza. No tengo ningún problema con eso, pero las artes pueden ayudarnos a percibir más riqueza: hay muchas maneras de ser feliz, hay muchas maneras de estar triste. Nosotros hacemos cosas, somos funcionales, pero en muchas ocasiones es útil preguntarnos cuál es nuestra experiencia, emoción, sentimiento, pensamiento o idea sobre una obra de arte. De esta manera, mi repertorio aumenta y tengo más gradaciones para incorporarlas a mis propias experiencias.

El arte me permite experimentar el mundo de una manera que es muy, muy importante para mí.

JLG: De tus palabras parece desprenderse que, cuando conectamos, dialogamos o conversamos con una obra de arte podría existir una especie de resonancia también con lo que vemos, oímos, percibimos... ¿Estarías de acuerdo?

LB: ¿Resonancia con el arte? Sí, totalmente de acuerdo. Resonancia es una palabra muy importante para mí y en mis investigaciones.

Con Robert Stake, por ejemplo, siento ese tipo de resonancia. La palabra resonancia la uso mucho en mi propio pensamiento. Es la resonancia del interior de mi psique, de mis sentimientos, de mis emociones hacia el mundo.

JLG: ¿Qué es, entonces, para ti lo que hace tan importante al arte? ¿Cómo podrías explicar esa manera de "ver" más allá de los simples objetos?

LB: Chris Higgins establece una diferencia entre «ver como» y «ver más». Cuando miro a mi ordenador, lo «veo como» mi ordenador, algo que es muy importante para mí, lo uso. También yo puedo ver, aquí en mi despacho: mi reloj, mis botas, el chocolate... Yo los reconozco por su utilidad. Esto es «ver como». Sin embargo, «ver más» me permite tomar algo de distancia, ir más allá de la utilidad. Me interesa la "distancia correcta" (no demasiado cerca, no demasiado lejos, o mejor, una yuxtaposición entre cerca y lejos).

Con el ordenador, pues necesito mi ordenador, estoy muy contenta de tener uno, y soy muy feliz de que funcione tan rápido... pero con el arte, es algo más allá de la funcionalidad y, ¿sabes?, yo no soy religiosa, pero creo que ése es el tipo de relación que hay que establecer con el arte, en el que las cosas tienen mucho más significado para cada uno. No quiero una vida hecha sólo de logros, de consecución de resultados. Me miro a mí misma, a los artículos que tengo publicados y al hecho de haber recibido cientos de invitaciones (por las que estoy muy agradecida) y disfruto escribiendo (y algunas veces sufro...) los artículos. Pero hay algo más allá de los logros y la funcionalidad.

Por ejemplo, en El Principito, una de las primeras cosas que hace el protagonista es describir una casa. Sus padres no comprenden nada y le dicen “¿cuánto cuesta?” y él dice "un millón de dólares". Entonces los padres dicen "iqué bonita casa!". Algunas veces tú podrías decir lo mismo de Liora, mirando a sus cientos de artículos y otras muchas cosas... "¡oh, qué grande es!”. Creo que eso me hace sentir querida. Pero, si nosotros fuéramos sólo eso... Sí, me encantan mis artículos o también podría hablar de otras personas, de cuánto dinero ganan o cuántos títulos tienen, pero para mí ésa no es la cuestión. Cuando veo a personas que realmente me importan, con las que tengo una buena conversación, puedo «ver más», puedo vibrar o, como decíamos antes, resonar con ellas, y eso provoca regocijo en mi espíritu y me siento muy, muy feliz.

JLG: Muchas gracias por dedicarme algo de tu tiempo y hacerme "ver" cómo contemplar el arte a través de tu experiencia. Creo que en tu manera de contemplar el arte 
๓) hay algo que nos impulsa a ser mejores personas, a

comprendernos más a nosotros mismos y la percepción que

tenemos del mundo que nos rodea. 


\section{Sobre el Entrevistador}

\section{José Luis Guerrero Valiente}

Profesor de música de secundaria en el IES Huerta del Rosario de Chiclana de la Frontera (Cádiz), posee el Grado medio de piano por el Conservatorio Profesional de Música Manuel de Falla de Cádiz, la Licenciatura en Historia y Ciencias de la Música por la Universidad de la Rioja y el Máster en "Educación Musical: Una Perspectiva multidisciplinar", por la Universidad de Granada.

Ha publicado en The International fournal of Technologies in Learning y presentado trabajos en los congresos de ISME, la Asociación Europea de Investigación Educativa (EERA) y el Congreso de Aprendizaje de Common Ground.

De septiembre a diciembre del 2012 realizó una estancia en la Universidad de Illinois en UrbanaChampaign gracias al programa de movilidad internacional para estudiantes de posgrado de la Universidad de Granada, tiempo durante el cual trabajó con Robert Stake, Liora Bresler y Yore Kedem, profesores de dicha Universidad.

Actualmente se encuentra realizando el doctorado del programa Oficial en Educación de la Universidad de Granada.

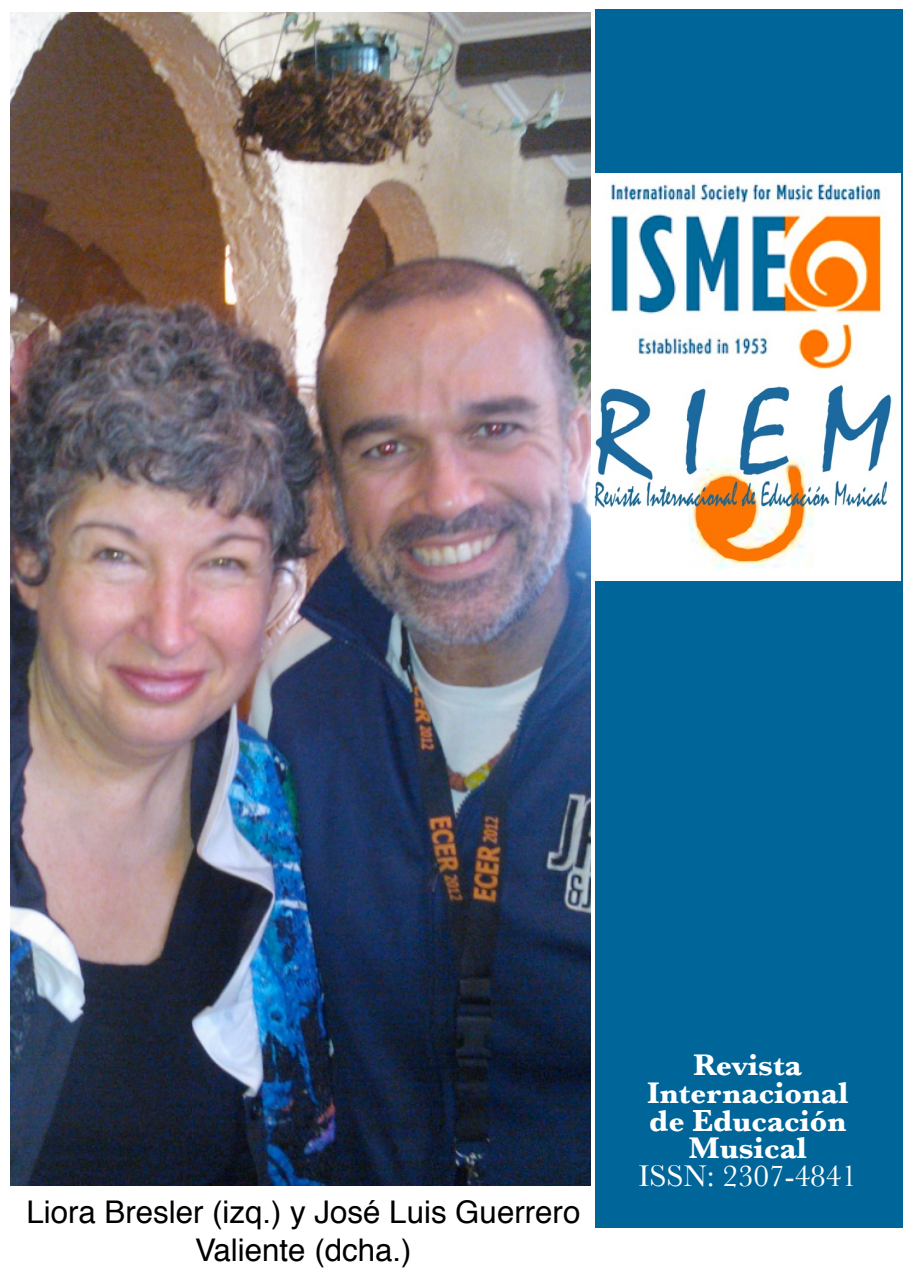

Valiente (dcha.)

\section{EQUIPO EDITORIAL}

Editor:

José Luis Aróstegui Plaza, Universidad de Granada (España)

\section{Editora Adjunta:}

Rosa María Serrano Pastor, Universidad de Zaragoza (España)

\section{Consejo Editorial}

María del Carmen Aguilar, Instituto Coral de Buenos Aires (Argentina)

Miquel Alsina Tarrés, Universidad de Gerona (España)

Graça Boal Palheiros, Instituto de Educación de Oporto (Portugal)

Rubén Gaztambide Fernández, Universidad de Toronto (Canadá)

Patricia Adelaida González, Universidad Autónoma de Chihuahua (México)

Claudia Gluschankof, Instituto Levinsky (Israel)

María Cecilia Jorquera Jaramillo, Universidad de Sevilla (España)

Gotzon Ibarretxe Txakartegi, Universidad del País Vasco (España)

Yore Kedem, Universidad de Illinois (Estados Unidos)

Saville Kushner, Universidad de Auckland (Nueva Zelanda)

Ana Laucirica Larrinaga, Universidad Pública de Navarra (España)

Ana Lucia Louro, Universidad Federal de Santa María (Brasil)

Isabel Cecilia Martínez, Universidad Nacional de La Plata (Argentina)
Teresa Mateiro, Universidad del Estado de Santa Catarina (Brasil)

María Teresa Moreno, Universidad Laval (Canadá)

Graça Mota, Instituto de Educación de Oporto (Portugal)

Oscar Odena, Universidad de Glasgow (Reino Unido)

Gabriel Enrique Rusinek Milner, Universidad Complutense de Madrid (España)

Patricia Sabbatella Riccardi, Universidad de Cádiz (España)

Favio Shifres, Universidad Nacional de La Plata (Argentina)

Christopher Suazo, Colegio Americano de Madrid (España)

Maria dels Àngels Subirats Bayego, Universidad de Barcelona (España)

António Ângelo Ferreira Vasconcelos, Instituto de Educación de Setúbal (Portugal)

Gloria Patricia Zapata Restrepo, Universidad de Antioquía (Colombia) 